This item was submitted to Loughborough's Research Repository by the author.

Items in Figshare are protected by copyright, with all rights reserved, unless otherwise indicated.

\title{
Stator winding fault diagnosis in synchronous generators for wind turbine applications
}

\section{PLEASE CITE THE PUBLISHED VERSION}

http://conferences.theiet.org/rpg-europe/index.cfm?

utm_source=redirect\&utm_medium=any\&utm_campaign=rpg-europe

\section{PUBLISHER}

IET

\section{VERSION}

AM (Accepted Manuscript)

\section{PUBLISHER STATEMENT}

This work is made available according to the conditions of the Creative Commons Attribution-NonCommercialNoDerivatives 4.0 International (CC BY-NC-ND 4.0) licence. Full details of this licence are available at: https://creativecommons.org/licenses/by-nc-nd/4.0/

\section{LICENCE}

CC BY-NC-ND 4.0

\section{REPOSITORY RECORD}

Ibrahim, Raed Khalaf, and Simon J. Watson. 2019. "Stator Winding Fault Diagnosis in Synchronous Generators for Wind Turbine Applications". figshare. https://hdl.handle.net/2134/22952. 


\title{
Stator Winding Fault Diagnosis in Synchronous Generators for Wind Turbine Applications
}

\author{
Raed Khalaf Ibrahim and Simon Watson \\ Centre for Renewable Energy Systems Technology (CREST), \\ Wolfson School of Mechanical, Electrical and Manufacturing Engineering, \\ Loughborough University, UK. \\ R.Ibrahim@lboro.ac.uk,S.J.Watson@lboro.ac.uk
}

\begin{abstract}
Wind turbine manufacturers have introduced to the market a variety of innovative concepts and configurations for generators to maximize energy capture, reduce costs and improve reliability of wind energy. For the purpose of improving reliability and availability, a number of diagnostic methods have been developed. Stator current signature analysis (SCSA) is potentially an effective technique to diagnose faults in electrical machines, and could be used to detect and diagnose faults in wind turbines. In this study, an investigation was conducted into the application of SCSA to detect stator inter-turn faults in an excited synchronous generator and a permanent magnet synchronous generator. It was found from simulation results that, owing to disruption of magnetic field symmetry and imbalance between the current flowing in the shorted turn and the corresponding diametrically opposite turn in the winding, certain harmonic components in the stator current clearly increased as the number of shorted turns increased. The findings are helpful to detect faults involving only a few turns without ambiguity, in spite of the difference in the configuration of the generators. As expected, because of the different type, configuration and operational condition of the two generators studied, detecting faults through the generator current signature requires a particular approach for each generator type.
\end{abstract}

Index Terms-Wind turbine, Generator, Condition monitoring, Current Signature, Fault signature, Fault detection, Diagnosis.

\section{INTRODUCTION}

Over the years, there has been much work to maximize energy capture, reduce costs and improve reliability of wind turbines [1]. With this work has come investment and the development of new technologies from wind turbine (WT) manufacturers. Among these technologies are the doubly fed induction generator (DFIG) with a three- stage gearbox which is the most common configuration at present, sharing the market with excited synchronous generators (EESGs) and the new arrivals, based on permanent magnet synchronous generators (PMSGs). Better design is of course one answer to increase the reliability and availability of WTs; the other is condition monitoring of the WT systems [2]. This allows for early detection of faults in wind turbines, allowing proactive decision making, minimizing downtime, and potentially forecasting the remaining useful life of ae component given a diagnosed fault.

A number of methods for WT condition monitoring have been proposed by researchers including the analysis of: vibration, oil quality, temperature, torque, acoustic emissions, fibre optics, and electrical output. However, each technique requires additional and expensive sensors or specialized tools. Moreover, there is a price to pay to access each WT in order to install the sensors, as well as lost revenue due to power outages associated with equipment installation and maintenance. Although SCSA is one of the preferred techniques to diagnose faults in electrical machines, it is not widely used by WT manufacturers. Many generator faults are bearing related and the lack of uptake could be because the physical link between rolling elements faults and fault signatures in electrical signals is not clearly identified. Also, it could be due to the difficulty in extracting fault signatures from the electrical signal which depends on the generator type, configuration and the operational condition. This paper considers two generator systems commonly used in WTs. Two models are implemented in MATLAB and simulated under a turn-to-turn short circuit fault as case studies to detect faults through the generator current signature. The first model represents a 2.0 MW WT with a PMSG (DeWind D9.1) and the second model represents a 2.0 MW WT with an EESG (DeWind D9.2). Both machine models are used to demonstrate fault detection capability for different generator configurations. The models allow for certain nonlinear and time-varying characteristics and take into account varying wind speeds similar to those experienced in WTs.

\section{GENERATOR CONFIGURATIONS IN WIND ENERGY CONVERSION SYSTEMS}

Wind energy conversion configurations can be classified into fixed speed and variable speed. In the early 1990s, most of the installed WTs were designed using a squirrel cage induction generator running close to fixed speed and directly connected to the grid [3], meaning that whatever the wind speed would be, the rotational turbine speed is fixed and determined by the frequency of the supply grid, the gear ratio and the generator design. During the past few years, the variable-speed WT has become the dominant type among the installed WTs based on DFIGs, sharing the market with EESGs and the new arrivals, based on PMSGs. In this section, the essential properties of the PMSG and EESG are briefly described. For a detailed analysis of generator types, the reader is referred to the standard literature in this field [4]. 


\section{A. Electrically-Excited Synchronous Generator}

The EESG is the predominant generator in the electrical power industry [5]. The stator windings of EESGs are directly connected to the grid and, the rotor winding is supplied with DC currents that create the rotor magnetomotive force and the rotor flux so that the EESG does not need any further reactive power compensation system unlike an induction generator. In normal operating conditions, the rotor revolves synchronously with the stator field. The synchronous rotation of the rotor is the reason for this type to be called synchronous generators. The speed of the synchronous generator is determined by the frequency of the rotating field and by the number of pole pairs of the rotor. Figure1 shows a schematic of an EESG machine such as the DeWind D9.2 having a $93 \mathrm{~m}$ rotor which drives a fixed speed EESG with a rated power of 2.0 MW. Due to its ability to generate at up to $13.8 \mathrm{kV}$, the generator can be directly connected to the grid through a synchronizing switch without the need of a power converter or a main power transformer. The fixed generator speed is achieved by converting the variable rotational speed from the WT rotor to a constant input speed by using a two stage helical /planetary gearbox and a variable speed Voith WinDrive hydrodynamic superimposed planetary gearbox. The heart of the WinDrive technology is a variable-speed hydrodynamic gearbox, and two main components of the WinDrive are the technique behind how it functions including a planetary gear combined and a hydrodynamic torque converter [6]. The planetary gear is designed as a superposition gear. It has the advantage that it does not need a power converter or a main power transformer. But the price to be paid for such a large, heavy and reliable gearbox design that has to provide the requirement for significant damping in the drive train.

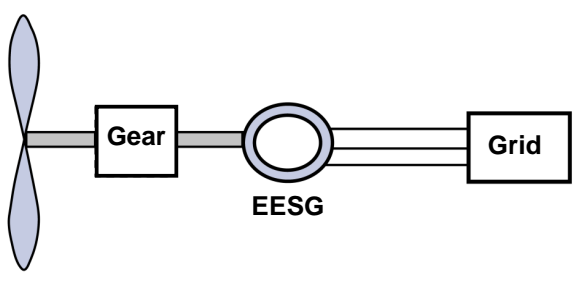

Fig. 1: Wind turbine system with EESG

\section{B. Permanent Magnet Synchronous Generator}

Instead of excitation windings, the rotor of a synchronous generator can have permanent magnets built into the rotor magnetic circuit. In this case, the rotor does not have any windings. PMSGs are favoured in WTs due to their light weight, high power density, and high efficiency [7]. The PMSG is often directly coupled with the rotor, eliminating the need for a gearbox and its associated cost and maintenance issues, whilst increasing the system reliability. They are not only used in small scale WTs but also in large MW applications. The PMSG is much more expensive than the DFIG of a similar size. However, it has one clear advantage compared with the DFIG: namely, it does not need reactive magnetizing current.
Figure2 shows a scheme using a PMSG where the magnetic field inside the generator is produced by permanent magnets on the rotor. Because there is no field winding in this generator, there is no associated $I^{2} R$ loss so that this type of generator has a very high efficiency, well above $90 \%$.

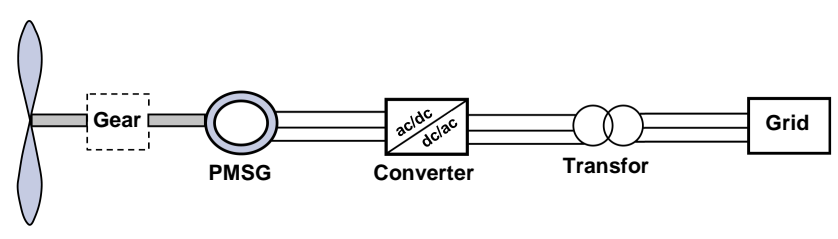

Fig. 2: Wind turbine system with PMSG

\section{DETECTION OF SHORT-CIRCUIT FAULT}

When an internal fault occurs on the stator winding it can cause severe damage to the machine and the system to which it is connected so that early detection of turn to turn short circuit faults during operation is essential to eliminate consequential damage. Unless detected early enough, it might lead to fire, explosion, and even loss of personnel [8]. It has been reported that a turn to turn short circuit results in a disruption of the magnetic field symmetry in the winding region of the machine as well as increasing the magnitudes of certain harmonic components [9]. Turn-to-turn faults are difficult to detect with confidence. Overcurrent and differential relays are generally agreed to be inadequate for this purpose. However, turn-to-turn faults can be detected by analyzing the current spectrum in the electrical machine fault will introduce sideband harmonics in the current signal [8]. The following subsections will describe how the fault sideband harmonics may occur during a turn to turn short circuit in EESG and PMSG current signals, and potentially how they may deviate from a healthy state.

1) Turn-to-turn fault in an EESG: In the case of an EESG with stator turn-to-turn faults, turn-to-turn faults can be detected by the presence of a spectral component at twice the fundamental supply frequency $2 f$, and the amplitude of this spectral component is directly related to the extension of the fault [10]. Other spectral components that can be observed in the stator line current are given by [11], [12].

$$
f_{c}=k f
$$

where $f_{c}$ and $f$ are detectable spectral components due to the fault and fundamental frequency components; $k$ is an even integer $(k=2,4,6)$. For example, on a machine supplied at $f=50 \mathrm{~Hz}$, the stator spectrum exhibits 100,200 and 300 $\mathrm{Hz}$ components because of turn-to-turn winding faults or supply unbalance, including single phasing.

2) Turn-to-turn fault in a PMSG: Current signature analysis has been studied extensively for fault detection in AC motors [13], [14]. According to [9], the occurrence of a turn-to-turn fault results in a disruption of magnetic field symmetry in the 
end winding region of the machine as well as increasing the magnitudes of certain harmonic components. This is because there is a severe imbalance between the current flowing in the shorted turn and the corresponding diametrically opposite turn in the winding. This type of fault will introduce sideband harmonics around the fundamental frequency in the machine current spectrum. It was later experimentally proven by Ebrahimi et al. [15] that turn-to-turn faults actually give rise to a sequence of such sidebands given by

$$
f_{c}=\left(1 \pm \frac{2 k_{s a}+1}{p}\right) \cdot f
$$

where $f_{c}$ and $f$ are detectable spectral components due to the fault and fundamental frequency components, respectively, $k$ is a constant coefficient $(k=0,1,2,3, \ldots)$ and $p$ the number of pole pairs.

\section{MODELLING AND SIMULATION}

A WT model was implemented in MATLAB/Simulink, including wind speed, rotor, pitch control system, drivtrain and generator model (see previous work [16]-[17]). Accordingly, the models of the PMSG and EESG will be only described here briefly.

\section{A. EESG model}

The detailed description and model equation derivation of EESGs can be found in most power system and electrical machine references [18]-[19]. Only the most important aspects of the modeling will be presented here. The system has been modeled and simulated in the Simulink toolbox extension of Matlab. Figure 3 shows the complete equivalent circuit representation of a three-phase EESG. A dc power source supplies the rotor field circuit. The field current $I_{f}$ is controlled by a variable resistance connected in series with the field winding. Each phase has an internal generated voltage with series resistance $R_{s}$ and series reactance $X_{s}$. Assuming balanced operation of the machine, the rms phase currents are equal to each other and shifted by 120 electrical degrees. The same thing is also true for the voltages.

EESGs operate only at synchronous speed; a constant speed that can be determined by the number of poles and the frequency of alternation of the armature-winding voltage. EESGs are called synchronous because their speed is directly related to the stator electrical frequency. Therefore, the synchronous speed can be expressed in $(\mathrm{rad} / \mathrm{s})$ as:

$$
\omega_{s}=\frac{\omega}{p}=\frac{2 \pi f}{p}
$$

or in (rev/min) as

$$
n_{s}=\frac{60 f}{p}
$$

where $\omega_{s}$ is the angular speed of the magnetic field (which is equal to the angular rotor speed of the synchronous machine), $\omega$ is the angular frequency of the electrical system, $f(\mathrm{~Hz})$ is the electrical frequency, $p$ pairs of poles and $n_{s}$ is the the synchronous speed in (rev/min) or rotational shaft speed.

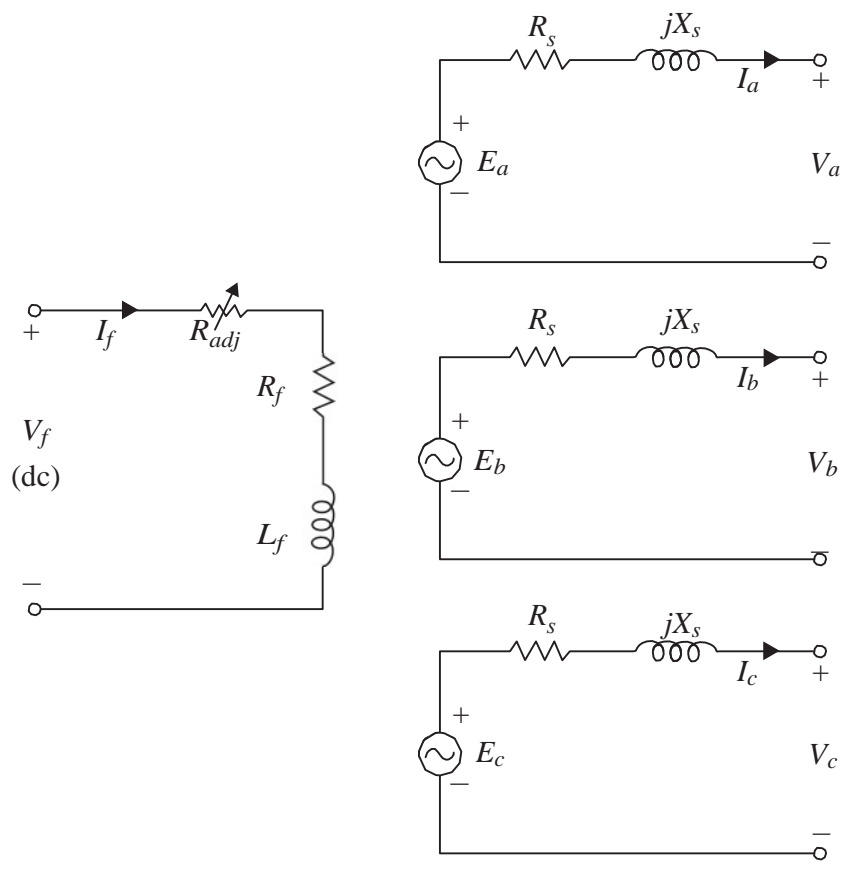

Fig. 3: Equivalent circuit representation of a three-phase EESG

According Faraday's Law the induced voltage in the stator winding can be expressed as:

$$
\begin{aligned}
& e_{a}(t)=E_{\text {max }} \sin \omega t \\
& e_{b}(t)=E_{\text {max }} \sin \left(\omega t-\frac{2 \pi}{3}\right) \\
& e_{c}(t)=E_{\text {max }} \sin \left(\omega t+\frac{2 \pi}{3}\right)
\end{aligned}
$$

The peak voltage in any phase of a three-phase stator is

$$
E_{\max }=\omega k N \phi=2 \pi f k N \phi
$$

where $N$ is the number of turns in each phase winding; $\phi$ is the flux per pole due to the excitation current $I_{f} ; k$ is the winding factor of the stator.

The voltage in RMS value is:

$$
E_{\text {max }}=\frac{2}{\sqrt{2}} \pi f k N \phi=4.44 f k N \phi
$$

This voltage is a function of the frequency or rotational speed, the flux that exists in the machine, and, of course, the construction of the machine itself.

\section{B. PMSG model}

A large number of papers describe the modeling of PMSGs [17]. PMSGs are ordinary synchronous machines with the field excitation provided by a permanent magnet. In other words, PMSGs provide the magnetic field so that there is no need for field windings, or supply current to the field. The PMSG operational principles are similar to that of EESGs, with the exception that they are run at different speeds, producing a variable-frequency output. Since the flux of the permanent magnet machine cannot be changed, they are not generally 
connected directly to the ac network. The power produced by the generator is initially variable voltage and frequency. This ac variable voltage should be rectified immediately to $\mathrm{dc}$, and the resultant dc power then inverted to ac with a fixed frequency and voltage. Thus, the PMSG model has been implemented based on previous equations with the following assumptions:

- The flux $(\phi)$ is fixed;

- The rotational speed $n_{s}$ is variable;

- The electrical frequency $f$ is proportional to the rotational speed;

- The induced voltages are proportional to the rotational speed;

As mentioned previously, the fundamental frequency in the PMSG is proportional to the rotational speed as explained in Equation (4) which clearly indicates that the current signals acquired from the generator terminals of the PMSG are always non-stationary so that it is essential to take into account the characteristic of the signal is varying with time. This will be briefly discussed in the results section.

The parameters for both generators used are detailed in Table 1.

TABLE I: The Parameters of PMSG and EESG.

\begin{tabular}{|l|l|}
\hline \multicolumn{2}{|c|}{ PMSG } \\
\hline Cut-In, Rated, Cut-Out Wind Speed & $3 \mathrm{~m} / \mathrm{s}, 12 \mathrm{~m} / \mathrm{s}, 25 \mathrm{~m} / \mathrm{s}$ \\
\hline Rated Tip Speed & $80 \mathrm{~m} / \mathrm{s}$ \\
\hline Rotor Diameter & $93 \mathrm{~m}$ \\
\hline Gearbox Ratio & $1: 108$ \\
\hline Line-Line Voltage (RMS) & $690 \mathrm{v}$ \\
\hline Grid Frequency & $50 \mathrm{~Hz}$ \\
\hline Pole Pairs & 2 \\
\hline Generator Speed (RPM) & $200-1500$ \\
\hline Stator phase resistance (ohm) & 0.026 \\
\hline Stator phase inductance (H) & 0.02587 \\
\hline \multicolumn{2}{|c|}{ EESG } \\
\hline Cut-In, Rated, Cut-Out Wind Speed & $3 \mathrm{~m} / \mathrm{s}, 12 \mathrm{~m} / \mathrm{s}, 25 \mathrm{~m} / \mathrm{s}$ \\
\hline Rated Tip Speed & $80 \mathrm{~m} / \mathrm{s}$ \\
\hline Rotor Diameter & $93 \mathrm{~m}$ \\
\hline Gearbox & $\mathrm{planetary}$ gearbox \\
\hline Line-Line Voltage (RMS) & $690 \mathrm{v}$ \\
\hline Frequency & $50 \mathrm{~Hz}$ \\
\hline Pole Pairs & 2 \\
\hline Rated Generator Speed (RPM) & 1500 \\
\hline Stator phase resistance (ohm) & 0.026 \\
\hline Stator phase inductance (H) & 0.02587 \\
\hline
\end{tabular}

\section{CASES}

This section will present case study simulations of an EESG and PMSG. It may be interesting to analyze the behavior of the models during simultaneous stator faults. Thus, we proceed with a series of tests using a few short circuited inter turns (SCIT) or with a resistive contact of several ohms between a high number of inter turns in the same phase. The following tests were carried out for both machines:

- healthy machine,

- short-circuit of 1 inter turn on phase a,

- short-circuit of 3 inter turns on phase a,

- short-circuit of 5 inter turns on phase a,
In order to observe the faults level, stator windings were modified to access the intermediate tap points. These tap points are distributed over phase a with the aim being able to short-circuit a number of inter turns in a quasi-geometric progression. In other words, the EESG and PMSG models are implemented with intermediate terminals of the winding, in order to emulate (or introduce) short-circuit faults with a low number of shorted turns: $(1,3$, and 5$)$ turns on the phase a as shown in Figure 4. While different tests are introduced for the two generators, the rated stator current and the fault current flowing in shorted turns are recorded to observe how the stator current will change in relation to the number of short-circuiting turns. Figure 5 shows simulation results of the evolution of the fault current flowing in the shorted turns as a function of the number of turns in the short circuit of EESG stator winding. As the number of shorted turns increases, the fault current amplitude becomes higher, inevitably might lead to rapid overheating in the conductors, and accordingly, undetected turn-to-turn faults could grow and culminate into major ones such as phase-to-ground or phase-to-phase faults.

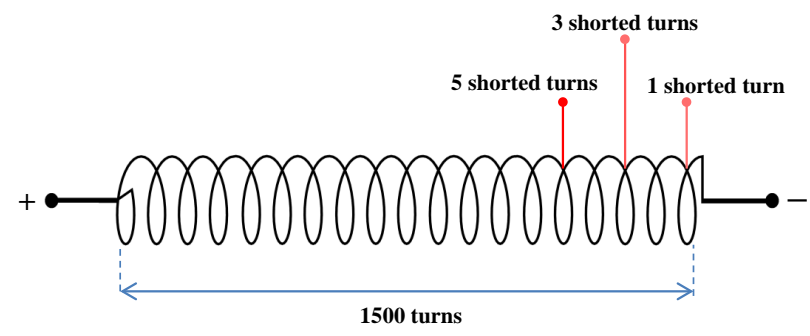

Fig. 4: Configuration of the access points of the stator windings of the EESG and PMSG models

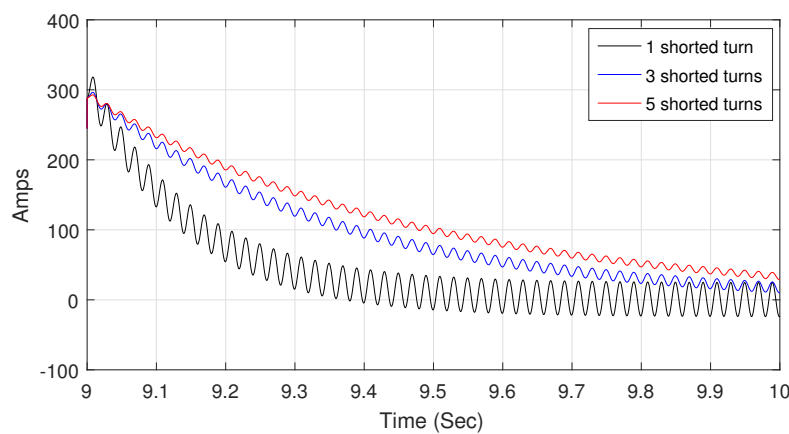

Fig. 5: Amplitude evolution in the fault current flowing in shorted turns in relation to the number of short-circuiting turns for an EESG.

\section{RESULTS AT CONSTANT SPEED}

Simulation results for a PMSG and EESG models under healthy condition and stator winding faults are discussed in this section. For each simulation result, data were recorded for 10 seconds at $5 \mathrm{kHz}$ sampling frequency and analysed using the fast Fourier transform (FFT) algorithm in MATLAB. Figure 6 
shows the fundamental harmonic of the stator current spectrum of the EESG machine operating at constant speed. We can see components with frequencies at $63.33 \mathrm{~Hz}$ and $31.66 \mathrm{~Hz}$, which are intentionally simulated to be present in the healthy machine spectrum as a dynamic eccentricity. Other spectral components given by the equation (1) are generated by the turn to turn faults in the EESG machine. The fault signature frequencies are labelled and identified as a function of the number of shorted turns. As the number of shorted turns increases, we notice a slight increase in the fault signature frequencies given by equation (1).
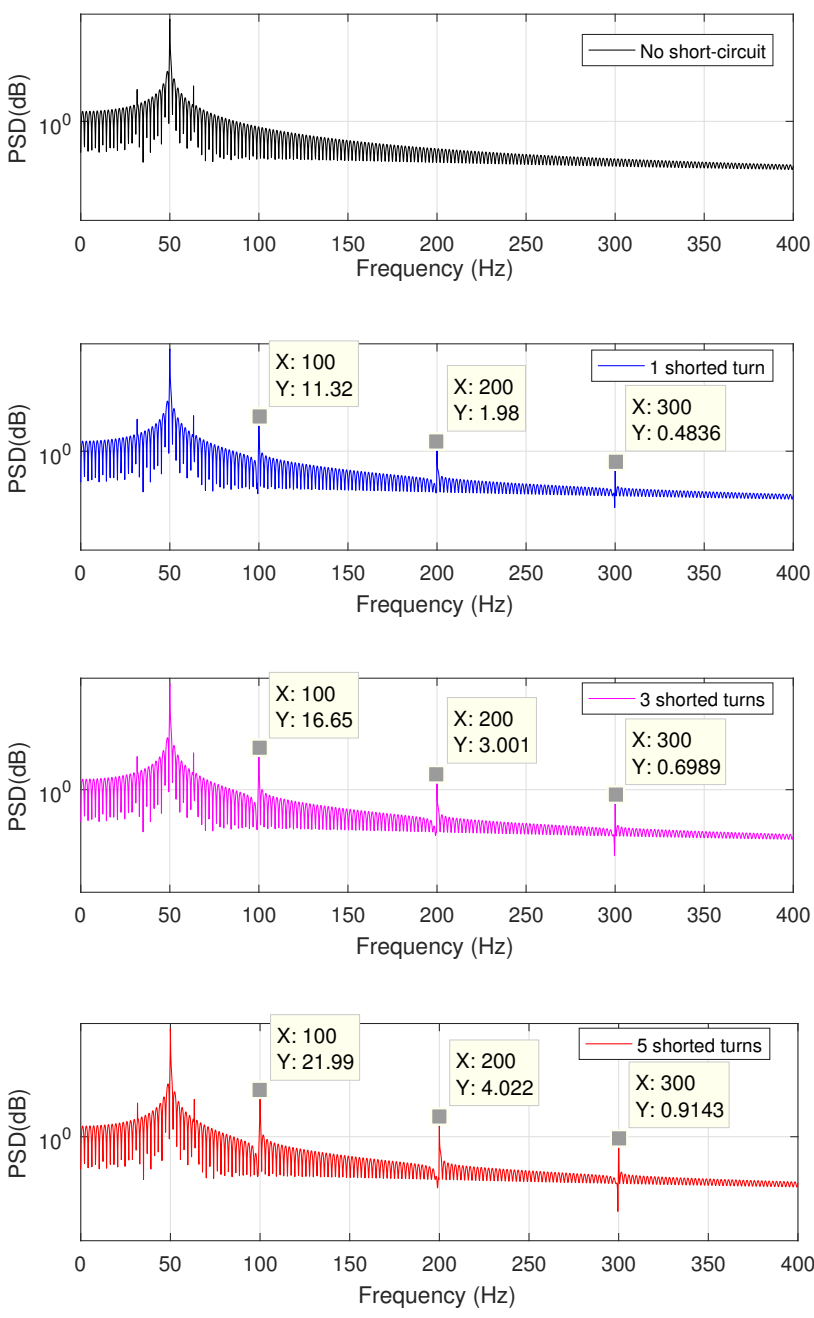

Fig. 6: Stator current spectrum around the fundamental harmonic for the EESG.

Figure 7 shows the stator current spectra of the PMSG after stator winding faults were applied, with the machine operating at constant speed. Turn to turn short circuit results in a disruption of the magnetic field symmetry in the winding region of the PMSG as well as increasing the magnitudes of certain harmonic components. The fault signature frequencies are clearly shown around the fundamental frequency and these frequencies are consistent for each case. These frequencies are defined by equation (2) and generated by the turn to turn faults in the PMSG machine. The amplitude of these frequencies are increased with the number of shorted turns. This might be a result of a severe imbalance between the current flowing in the shorted turn and the corresponding diametrically opposite turn in the winding.
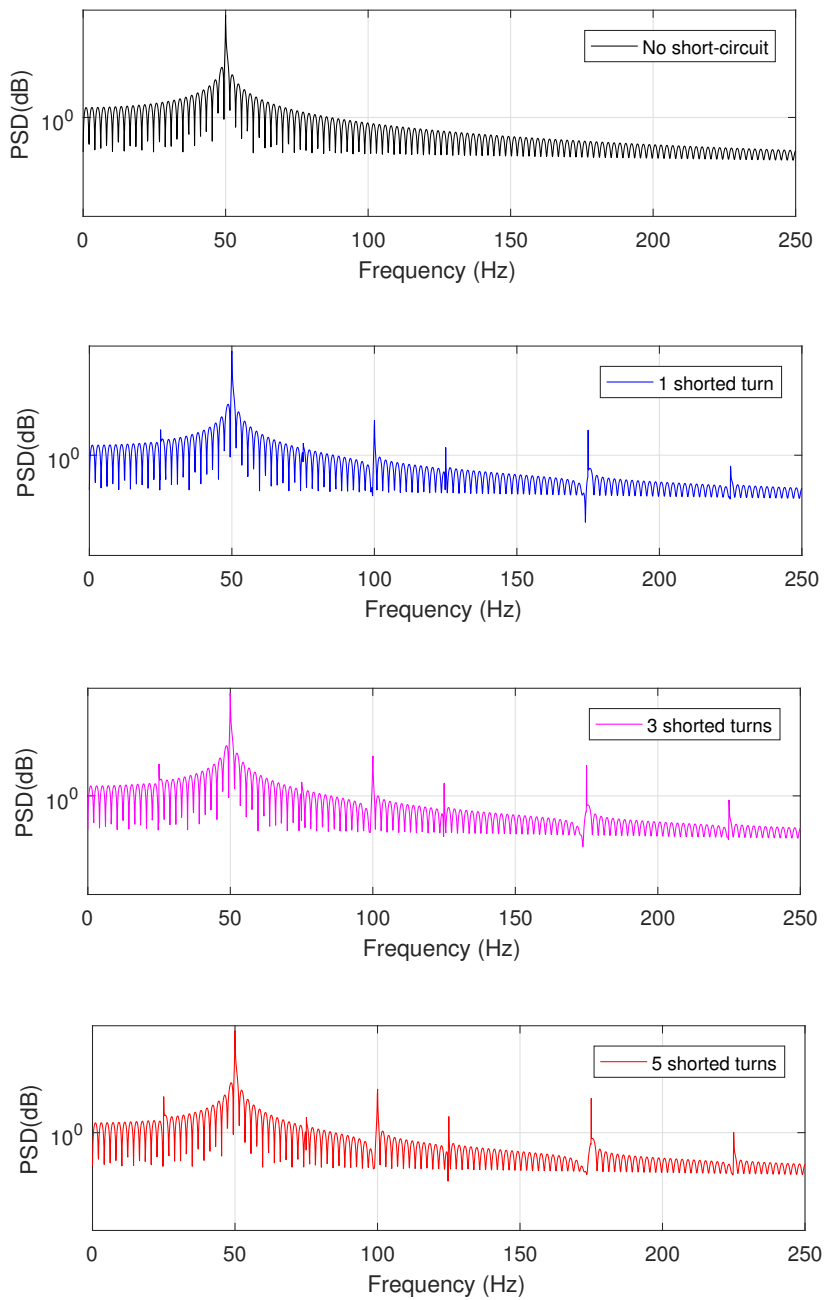

Fig. 7: Stator current spectrum around the fundamental harmonic for the PMSG operating at fixed speed.

Generally PMSGs operate at variable speed, therefore the model was run at variable speed to investigate the potential for fault frequency tracking. Figure 8 shows the stator current spectra for the healthy PMSG and with increasing shorted turn faults operating at variable speed. Although the fault signature frequencies are still seen in the spectrum, it is difficult to distinct between the fault levels in relation to the number of shorted turns, because the rotational speed in the PMSG is proportional to the wind speed so that the number of harmonics in the PMSG spectrum will increase with the rotational speed, as described by Equation (4). Consequently, the fault signature frequencies are buried in wide-band dominant frequency components (i.e. harmonics due to variable rotational speeds) of the current signal that are irrelevant to the fault. 

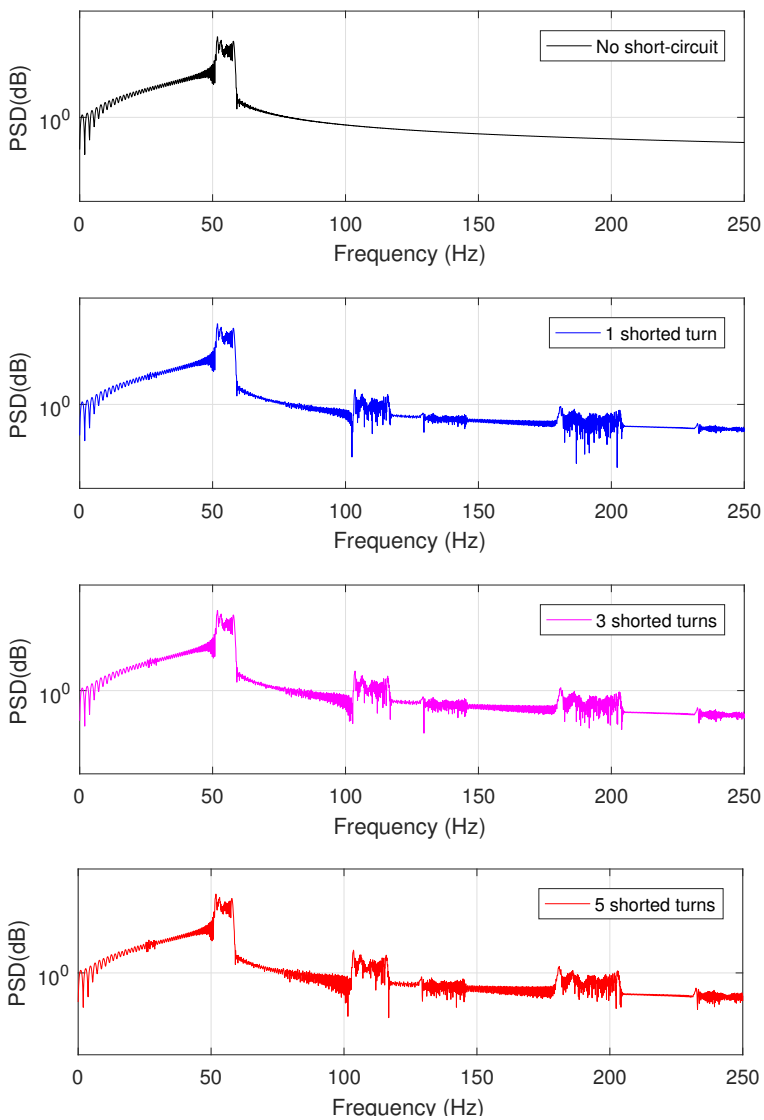

Fig. 8: Stator current spectrum around the fundamental harmonic for the PMSG operating at variable speed.

\section{CONCLUSION}

This paper analyzed the stator winding fault behavior of synchronous machines. Based on the analyses, approximate equations for the fault current flowing in shorted turns have been derived. The results obtained from the approximate equations have been compared to the results of time-domain and frequency-domain simulations. The results showed the frequencies inherent to shorted turn faults occur in the spectra of each machine. Although turn-to-turn faults have led to increase the amplitude of the fault current flowing in shorted turns, the rated current amplitude does not change so that it is difficult to detect with confidence using overcurrent and differential relays. However, we have noticed that the current analysis gives good results in the frequency-domain. It should be pointed out here that this type of fault is problematic to diagnose in time domain. Another important conclusion of this work is that stator winding faults have a particular signature that should be detectable in current signals in an EESG because this machine is operating at constant speeds, while the current signals in the PMSG includes harmonics, which are due to the variation of wind speed as well as those related to the presence of the electrical fault. Ultimately, stator current signature analysis could be used to detect and diagnose faults in a fixed speed WT. The technique can be used to detect faults in a variable speed machine but may require an alternative analysis technique (e.g wavelet or short-term Fourier transform analysis) to detect the magnitude of such faults.

\section{REFERENCES}

[1] P. Tchakoua, R. Wamkeue, T. A. Tameghe, and G. Ekemb, "A review of concepts and methods for wind turbines condition monitoring," in Computer and Information Technology (WCCIT), 2013 World Congress on, pp. 1-9, IEEE, 2013.

[2] M. Wilkinson, B. Darnell, T. van Delft, and K. Harman, "Comparison of methods for wind turbine condition monitoring with scada data," Renewable Power Generation, IET, vol. 8, no. 4, pp. 390-397, 2014.

[3] $\mathrm{H}$. Li and Z. Chen, "Overview of different wind generator systems and their comparisons," Renewable Power Generation, IET, vol. 2, pp. 123 138, June 2008.

[4] J. Machowski, J. Bialek, and J. Bumby, Power system dynamics: stability and control. John Wiley \& Sons, 2011.

[5] T. Ackermann et al., Wind power in power systems, vol. 140. Wiley Online Library, 2005.

[6] Voith Turbo Wind GmbH and Co. KG, A Unique Solution to Generating Electricity from the Wind. WinDrive Technology, [Online]: http://resource.voith.com/vt/publications/downloads/voith-windrive-forwind-turbines.pdf.

[7] X. Yang, D. Patterson, and J. Hudgins, "Permanent magnet generator design and control for large wind turbines," in Power Electronics and Machines in Wind Applications (PEMWA), 2012 IEEE, pp. 1-5, IEEE, 2012.

[8] S. Nandi, S. Choi, and H. Meshgin-kelk, "Electric machines: Modeling, condition monitoring, and fault diagnosis," 2012.

[9] J. Penman, H. Sedding, B. Lloyd, and W. Fink, "Detection and location of interturn short circuits in the stator windings of operating motors," Energy conversion, ieee transactions on, vol. 9, no. 4, pp. 652-658, 1994.

[10] S. Cruz and A. M. Cardoso, "Stator winding fault diagnosis in threephase synchronous and asynchronous motors, by the extended park's vector approach," Industry applications, IEEE Transactions on, vol. 37, no. 5, pp. 1227-1233, 2001.

[11] P. Tavner, "Review of condition monitoring of rotating electrical machines," Electric Power Applications, IET, vol. 2, no. 4, pp. 215-247, 2008.

[12] G. Singh et al., "Experimental investigations on induction machine condition monitoring and fault diagnosis using digital signal processing techniques," Electric Power Systems Research, vol. 65, no. 3, pp. 197221, 2003.

[13] S. Nandi and H. Toliyat, "Condition monitoring and fault diagnosis of electrical machines-a review," in Industry Applications Conference, 1999. Thirty-Fourth IAS Annual Meeting. Conference Record of the 1999 IEEE, vol. 1, pp. 197-204 vol.1, 1999.

[14] S. Nandi, H. Toliyat, and X. Li, "Condition monitoring and fault diagnosis of electrical motors-a review," Energy Conversion, IEEE Transactions on, vol. 20, pp. 719-729, Dec 2005.

[15] B. M. Ebrahimi and J. Faiz, "Feature extraction for short-circuit fault detection in permanent-magnet synchronous motors using stator-current monitoring," Power Electronics, IEEE Transactions on, vol. 25, no. 10, pp. 2673-2682, 2010

[16] R. K. Ibrahim and S. Watson, "Effect of power converter on condition monitoring and fault detection for wind turbine," in Power Electronics, Machines and Drives, 2016. PEMD 2016. 8th IET Conference on, IET, 2016.

[17] R. K. Ibrahim and S. Watson, "Wind turbine simulation model for the study of combined mechanical and electrical faults," in Scientific Track Proceedings of European Wind Energy Association. EWEA, 2015.

[18] I. Tabatabaei, J. Faiz, H. Lesani, and M. T. Nabavi-Razavi, "Modeling and simulation of a salient-pole synchronous generator with dynamic eccentricity using modified winding function theory," IEEE Transactions on Magnetics, vol. 40, pp. 1550-1555, May 2004

[19] I. Iglesias, L. Garcia-Tabares, and J. Tamarit, "A d-q model for the selfcommutated synchronous machine considering the effects of magnetic saturation," Energy Conversion, IEEE Transactions on, vol. 7, no. 4, pp. 768-776, 1992. 